OPEN ACCESS

Edited by:

Teun J. De Vries,

VU University Amsterdam,

Netherlands

Reviewed by:

Natasha Appelman-Dijkstra,

Leiden University Medical Center,

Netherlands

Michaël R. Laurent,

University Hospitals Leuven, Belgium

*Correspondence:

Nicholas G. Norwitz

nicholas.norwitz@dpag.ox.ac.uk

Specialty section:

This article was submitted to

Bone Research,

a section of the journal

Frontiers in Endocrinology

Received: 04 February 2019

Accepted: 06 March 2019

Published: 26 March 2019

Citation:

Norwitz NG, Mota AS, Misra M and Ackerman KE (2019) LRP5, Bone Density, and Mechanical Stress: A Case Report and Literature Review. Front. Endocrinol. 10:184. doi: 10.3389/fendo.2019.00184

\section{LRP5, Bone Density, and Mechanical Stress: A Case Report and Literature Review}

\author{
Nicholas G. Norwitz ${ }^{1,2 *}$, Adrian Soto Mota ${ }^{1}$, Madhusmita Misra ${ }^{2,3,4}$ and \\ Kathryn E. Ackerman ${ }^{2,4,5}$
}

${ }^{1}$ Department of Physiology, Anatomy and Genetics, University of Oxford, Oxford, United Kingdom, ${ }^{2}$ Harvard Medical School, Boston, MA, United States, ${ }^{3}$ Division of Pediatric Endocrinology, Massachusetts General Hospital, Boston, MA, United States, ${ }^{4}$ Neuroendocrine Unit, Massachusetts General Hospital, Boston, MA, United States, ${ }^{5}$ Divisions of Sports Medicine and Endocrinology, Boston Children's Hospital, Boston, MA, United States

The Wnt- $\beta$-catenin pathway receptor, low-density lipoprotein receptor-related protein 5 (LRP5), is a known regulator of bone mineral density. It has been hypothesized that specific human polymorphisms in LRP5 impact bone density, in part, by altering the anabolic response of bone to mechanical loading. Although experiments in animal models support this hypothesis, there is limited evidence that LRP5 polymorphisms can alter the anabolic response of bone to mechanical loading in humans. Herein, we report a young male who harbors a rare LRP5 missense mutation (A745V) and who provides potential proof of principle for this mechanotransduction hypothesis for low bone density. The subject had no history of fractures until age 18, a year into a career in competitive distance running. As he continued to run over the following 2 years, his mileage threshold to fracture steadily and rapidly decreased until he was diagnosed with severe osteoporosis (lumbar spine BMD Z-score of -3.2). By contextualizing this case within the existing LRP5 and mechanical stress literature, we speculate that this represents the first documented case of an individual in whom a genetic mutation altered the anabolic response of bone to mechanical stress in a manner sufficient to contribute to osteoporosis.

Keywords: bone mineral density, LRP5, mechanical stress, osteoporosis, Wnt- $\beta$-catenin signaling

\section{BACKGROUND}

Low-density lipoprotein receptor-related protein 5 (LRP5) is a 1,615 amino acid transmembrane receptor for the conserved Wnt- $\beta$-catenin signaling pathway, a pathway known to regulate bone metabolism in humans. In canonical Wnt- $\beta$-catenin signaling, a Wnt ligand binds to a binding site created by the $1^{\text {st }}$ and $3^{\text {rd }} \beta$-propeller domains of LRP 5 and to its co-receptor, Frizzled. This enables LRP5 to sequester a cytoplasmic destruction complex and, thereby, prevent the degradation of the protein $\beta$-catenin. Subsequently, $\beta$-catenin translocates into the nucleus, where it interacts with TCF/LEF family transcription factors and alters gene expression to promote bone formation (1) (Figure 1A). Genome-wide association studies (GWAS) have repeatedly classified LRP5 as a key mediator of bone mineral density (BMD) (2-4), including the largest GWAS to date, which identified LRP5 as a BMD and fracture risk locus at a significance level of $\mathrm{p}<1.0 \times 10^{-21}$ (5). 


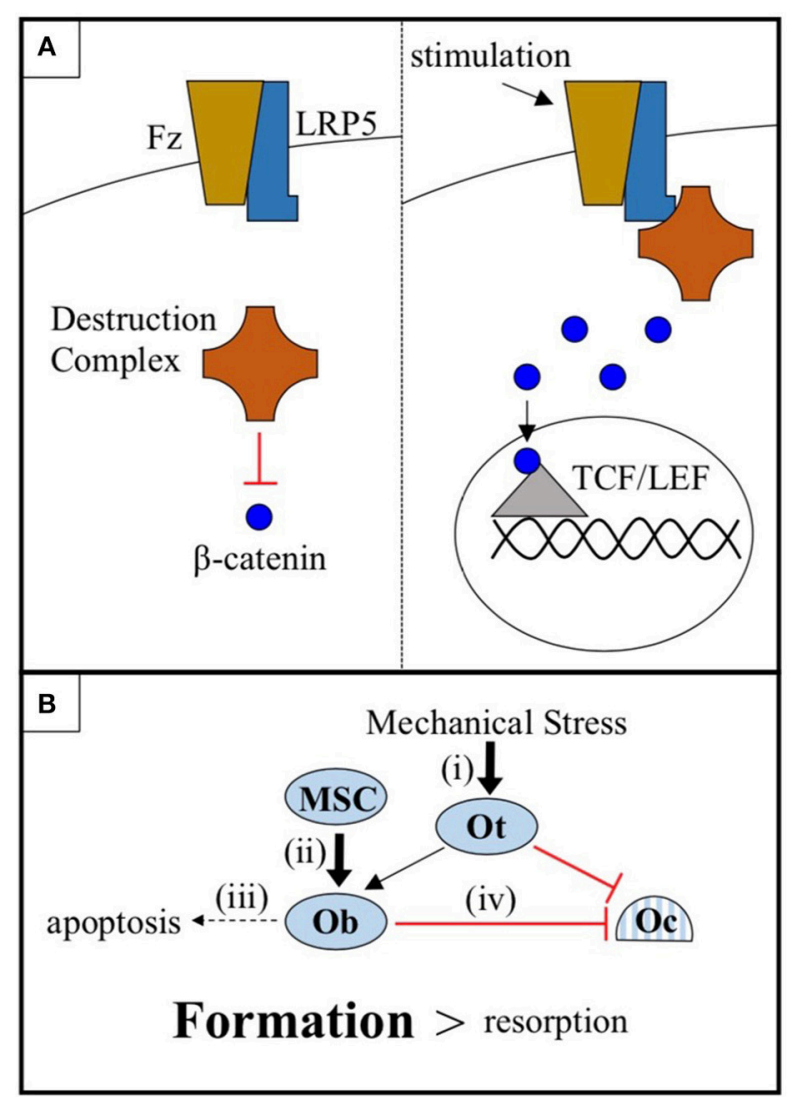

FIGURE 1 | (A) The cytoplasmic destruction complex constitutively targets $\beta$-catenin for degradation. Mechanical or chemical stimulation of the Wnt- $\beta$-catenin pathway receptor pair LRP5-Frizzled (Fz), in cells of the osteoblast linage, causes LRP5 to sequester the destruction complex, allowing $\beta$-catenin to accumulate and translocate to the nucleus where it interacts with TCF/LEF family transcription factors and promotes osteogenic gene expression. (B) Osteocytes (Ot) sense mechanical stress and respond by increasing Wnt- $\beta$-catenin signaling and coordinating the anabolic activities of osteoblasts (Ob) and the catabolic activities of osteoclasts (Oc). Wnt- $\beta$-catenin signaling, in addition to (i) sensitizing osteocytes to mechanical stress, (ii) promotes the differentiation of mesenchymal stem cells (MSC) into osteoblasts, (iii) prevents osteoblast apoptosis, and (iv) increases osteoprotegerin expression by osteoblasts, thus inhibiting osteoclastmediated bone resorption. The net effect is a shift in favor of bone formation over bone resorption.

LRP5 mutations are known to cause disorders of both low and high BMD. Recessive loss-of-function mutations in LRP5 cause osteoporosis-pseudoglioma syndrome (OPPG), a condition characterized by severe osteoporosis and occasional ocular abnormalities $(1,6)$, whereas gain-of-function mutations in LRP5 are associated with abnormally high BMD (7). Furthermore, LRP5 demonstrates haploinsufficiency (6, 8-11). In fact, dominant loss-of-function mutations in LRP5 are among the most common causes of familial exudative vitreoretinopathy (FEVR), a congenital eye defect that often presents with a comorbid low BMD phenotype $(10,11)$. Of note, LRP5 haploinsufficiency appears to affect BMD in men more severely than in women (12-15). In addition to GWAS and clinical associations, LPR5 heterozygous $\left(L P R 5^{+/-}\right)$mouse models reliably exhibit low BMD (16-18). Consistent with data from human studies, the loss-of-function phenotype is more severe in male mice than in female mice, with male mice exhibiting lower relative BMDs, shortened femurs during their youth, and a reduced osteogenic response to mechanical stress (17).

There are a number of mechanisms by which LRP5mediated Wnt- $\beta$-catenin signaling in cells of the osteoblast lineage may promote bone growth. These include (i) sensitizing osteocytes to mechanical stress, (ii) promoting the differentiation of mesenchymal stem cells (MSC) into osteoblasts, (iii) preventing osteoblast apoptosis, and (iv) increasing osteoblast expression of osteoprotegerin to decrease osteoclastogenesis (1924) (Figure 1B). While each of these mechanisms likely plays a part in mediating the regulatory effects of the LRP5 protein on BMD, the mechanical stress model (i) is the focus of this report. There is an abundance of mouse data to support this model. First, LRP5 gain-of-function mutations in mice do not appear to increase basal rates of bone formation in the absence of mechanical stimulation, but more than double bone formation in response to mechanical stress $(25,26)$. Second, LRP5 gainof-function enhances the expression of bone formation genes in response to mechanical stress (24). Third, conditional knockout of LRP5 in murine osteocytes, cells which are believed to serve as the mechanosensors of bone, diminishes the osteogenic response to mechanical stress, whereas activation of Wnt- $\beta$ catenin signaling in osteocytes is sufficient to increase the osteogenic response (27-29). Thus, data from mice support a model in which the LRP5 receptor influences BMD, at least in part, by regulating mechanotransduction.

Three clinical observations of patients bearing LRP5 mutations also support the mechanical stress model. First, LRP5 mutations do not appear to affect calcium homeostasis, anabolic or catabolic hormones, collagen synthesis, or basal levels of bone turnover, even in patients with severe osteoporosis (9, 13). Second, LRP5 gain-of-function mutations can increase BMD without affecting bone shape or causing bony lesions, which are observed in genetic conditions that simply increase basal osteoblast activity or decrease basal osteoclast activity (30). Third, LRP5 gain-of-function mutations cause the greatest enhancement of BMD in load bearing bones (30).

Two population-based studies add yet another level of support to the mechanical stress model. In a subset of 868 men from the Framingham Offspring Study Cohort, a polymorphism in exon 10 of LRP5 appeared to negatively affect the interaction between physical activity and BMD. Specifically, men homozygous for the common allele exhibited a positive correlation between physical activity and BMD; heterozygous men exhibited no correlation; and men homozygous for the less common allele exhibited a negative correlation between physical activity and BMD (31). Similar data were reported from the Odense Androgen Study. In this study of 783 men aged 20-30, the LRP5 polymorphisms A1330V and V667M were associated with low BMD in physically active men, but not in sedentary men (32). Although these two independent studies each suggest that polymorphisms in LRP5 can alter the anabolic response of bone to mechanical stress in men, they were limited by the fact that they assessed physical activity using questionnaires. 
We report a 23-year-old male ex-distance runner who presented with primary osteoporosis and a rare LRP5 variant, A745V in exon 10, at age 20. His mutation, medical history, and athletic history complement and build upon the mouse models, clinical observations, and epidemiological data introduced above. In brief, this case represents potential proof of principle for the mechanical stress model and suggests the possibility that LRP5 mutations contribute to low $\mathrm{BMD}$, in part, by blunting the anabolic response of bone to mechanical stress.

\section{CASE REPORT}

The Caucasian male subject was the product of an uncomplicated pregnancy, although he did exhibit shortened femurs in utero, similar to LRP5 loss-of-function male mice (17). He demonstrated no signs of any chronic health condition during his highly active youth or adolescence, during which he engaged in a variety of sports, including basketball, soccer, rugby, and martial arts. He began competitive distance running at age 17. For over 1 year, he consistently ran between 60 and 80 miles per week without sustaining any bone injuries. At age 18 , he sustained a stress fracture in his right lateral tibial plateau. Subsequent to this initial stress fracture, he began to experience stress fractures at progressively lower mileage thresholds. After fracture resolution, physical therapy, and a gradual return to running, he sustained further tibial, femoral, and sacral alar stress fractures when running 40, 20, and even 10 miles per week, consistent with the notion that his bones were weakening as he continued to run (Figure 2A).

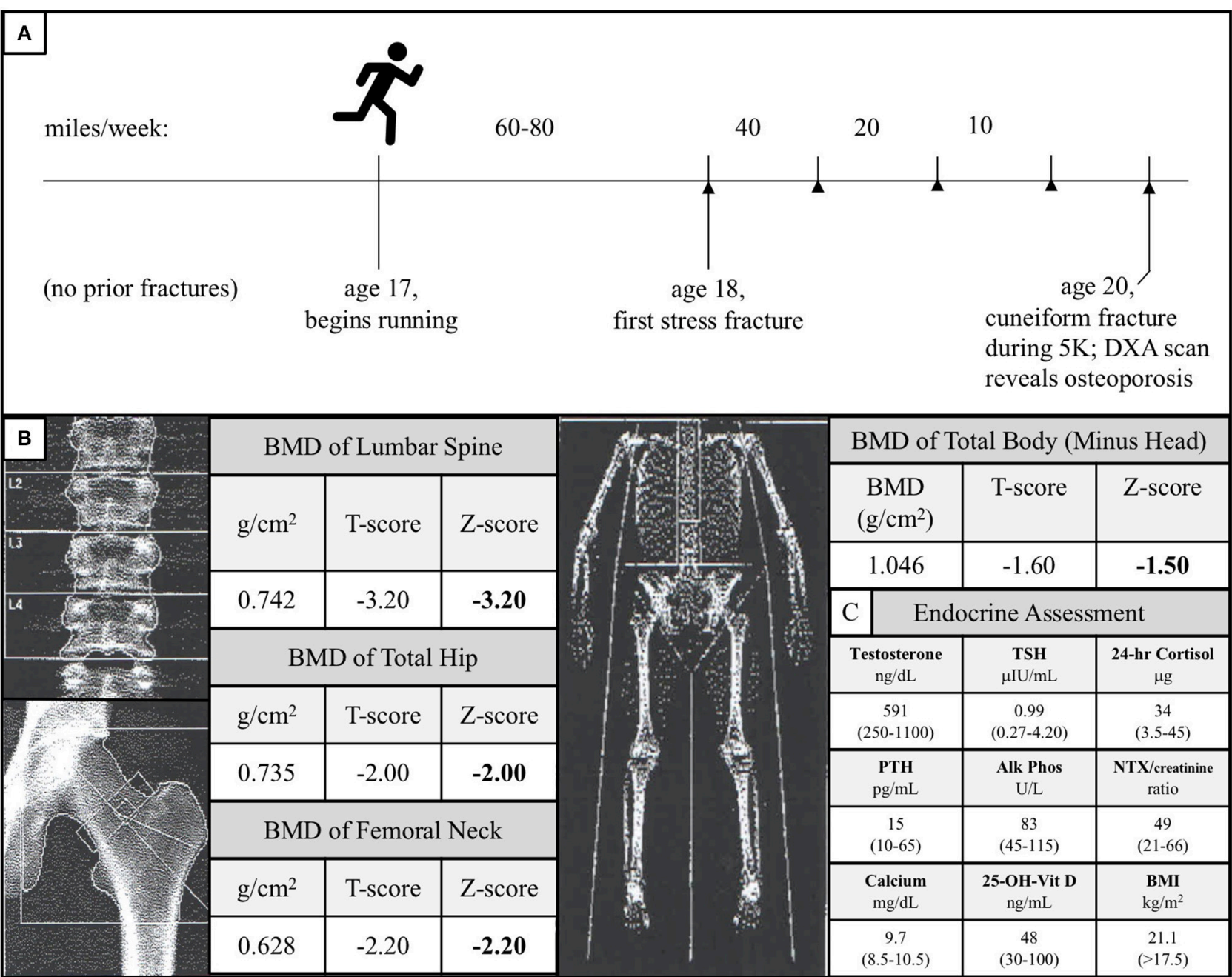

FIGURE 2 | (A) Diagram of the subject's running and stress fracture history. The subject had no history of fractures during his childhood and began distance running at age 17. He successfully ran 60-80 miles per week for over 1 year before experiencing his first fracture in his right lateral tibial plateau. Over the subsequent years, as he continued to run, his mileage threshold to fracture decreased precipitously (stress fractures are represented by arrowheads). At age 20, he fractured his right cuneiform during a 5-kilometer road race. A follow-up of the unusual foot fracture revealed osteoporosis. (B) DXA scan of the subject's lumbar spine, total hip, femoral neck, and total body (minus head) at time of diagnosis. These data are consistent with the notion that the subject's load-bearing bones failed to adapt to the mechanical stress of running. (C) Endocrine assessment at time of diagnosis. Reference ranges are given in parentheses and BMl $>17.5 \mathrm{~kg} / \mathrm{m}^{2}$ is used because this threshold is a surrogate marker for Relative Energy Deficiency in Sport (RED-S) in men (33, 34). 
At age 20, he sustained a complete fracture of his right cuneiform during a 5-kilometer run. A dual-energy X-ray absorptiometry (DXA) scan was performed given this history of recurrent fractures and this revealed a lumbar spine BMD Zscore of -3.2 , total hip BMD Z-score of -2.0, femoral neck BMD Z-score of -2.2 , and total body (minus head) BMD Z-score of -1.5 (Figure 2B). At the time of diagnosis, the subject had a normal BMI $\left(21.1 \mathrm{~kg} / \mathrm{m}^{2}\right)$, normal resting metabolic rate $(1,613$ $\mathrm{kcal} /$ day, measured by respirometry vs. 1,604 kcal/day, calculated using the Harris-Benedict equation), normal testosterone, TSH, 24-h urine free cortisol, PTH, alkaline phosphatase, urinary Nterminal telopeptide/creatinine, calcium, and 25-OH-Vitamin D (Figure 2C). All other electrolytes, hormones, and kidney and liver function tests were unremarkable, and the subject, now 23, has exhibited no meaningful signs of endocrine dysfunction in the years since initial evaluation.

A genetic screen revealed an undocumented paternallyinherited polymorphism (A745V) in the LRP5 gene. His father, a 54-year-old with a BMI of $37.2 \mathrm{~kg} / \mathrm{m}^{2}$, did not exhibit low BMD at the lumbar spine, total hip, or femoral neck (T-scores of 0.0 , 0.9 , and 0.1 , respectively); however, the father did exhibit a radial BMD T-score of -2.6 (age-adjusted Z-score of -2.0 ). The subject completed a 13-month course of teriparatide, which increased his lumbar spine BMD Z-score from -3.2 to -2.7 , and he is currently on denosumab.

The subject's only other health condition is ulcerative colitis, which was diagnosed at age 22, 4 years after his first fracture. The colitis is mild and localized to the cecum and sigmoid colon. As the subject never exhibited evidence of malabsorption/malnutrition or systemic inflammation (his high sensitivity CRP was consistently measured to be low both before and after his colitis diagnosis), was never on chronic glucocorticoids, and had absolutely no symptoms of this condition at the time that he was having the fractures, it is unlikely that his ulcerative colitis contributed to his low BMD. This opinion was unanimously shared by three independent gastroenterological consults.

\section{DISCUSSION}

The properties of the $\mathrm{A} 745 \mathrm{~V}$ variant suggest that it likely contributed to the subject's osteoporosis. A745V is extremely rare, with a minor allele frequency of 0.0008 in the Genome Aggregation Database (254/282476 alleles; 0 homozygotes), and is perfectly conserved among mammals, birds, snakes, fish, and even the Drosophila homolog of LRP5. It is located within the Wnt-ligand-binding $3^{\text {rd }} \beta$-propeller domain, adjacent to two other residues (N740, from the Framingham Study, and W734) mutations in which are also associated with low BMD in humans $(6,31)$ (Figure 3). Other alanine to valine missense mutations in LRP5 have been reported to contribute to low BMD. The A745V variant was predicted to be consequential in in silico models and was reported to contribute to a case of FEVR, which is often associated with low $\operatorname{BMD}(3,32,35)$ (Figure 4).

Despite the evidence supporting the consequence of the A745V variant mentioned in the previous paragraph, the proposition that this inherited genetic mutation was a major contributor to the subject's osteoporosis raises two important questions: (1) Why is there a discrepancy between the subject's $\mathrm{BMD}$ and that of his father? (2) If the subject's low BMD

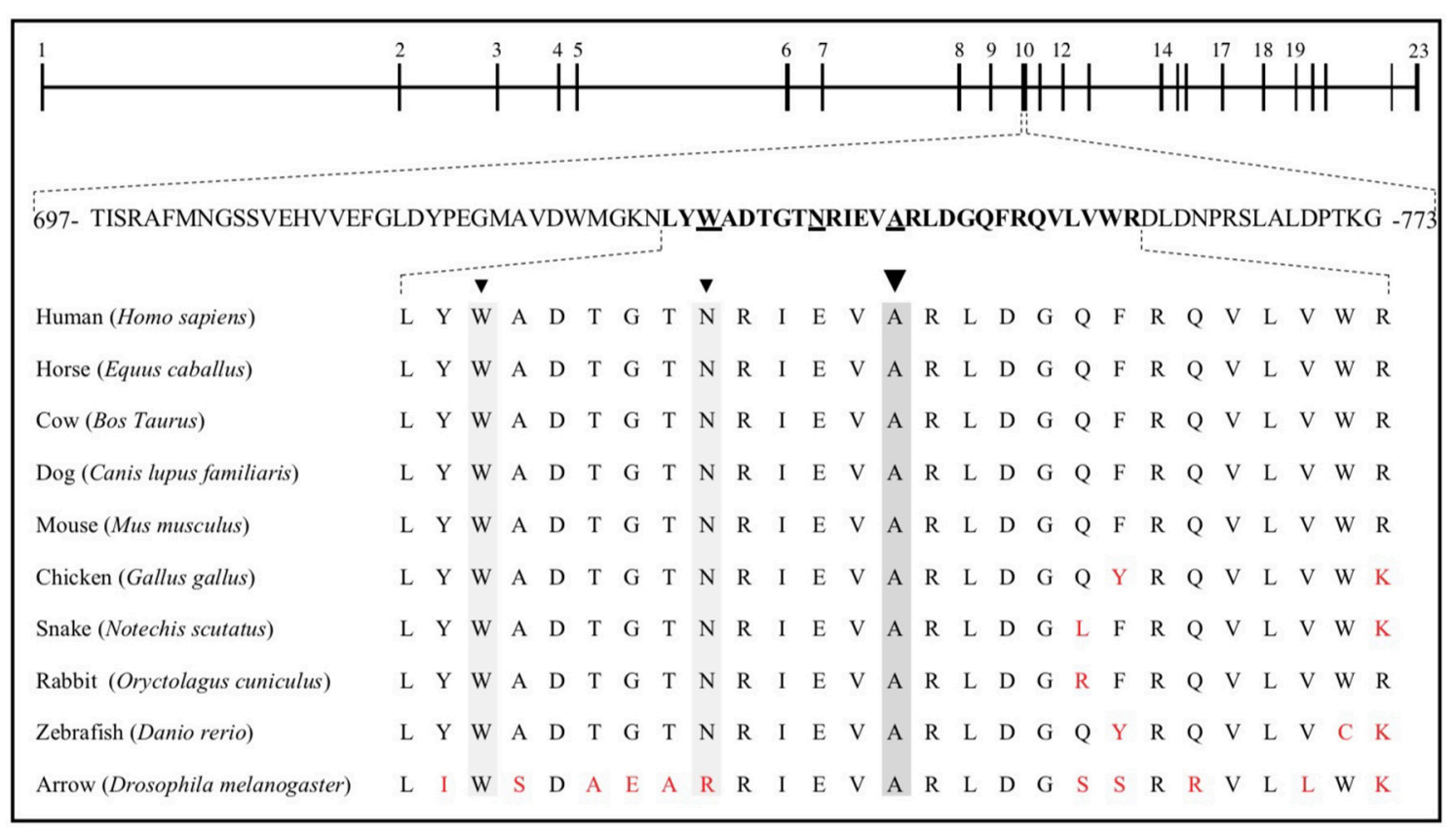

FIGURE 3 | The LRP5 gene is composed of 23 exons, coding for 1,615 amino acids. Exon 10 includes residues 697 to 773,27 of which are sequence aligned with the corresponding horse, cow, dog, mouse, chicken, snake, rabbit, and zebrafish LRP5 sequences, as well as with that of the homologous protein in Drosophila, arrow. W734 (6), N740 (31), and A745 are underlined and identified by arrowheads. Red letters represent nonconserved residues. 

i. $\quad$ GWAS identify LRP5 as a BMD-associated locus, $\mathrm{p}<1.0 \times 10^{-21}$

\section{LRP5}
ii. $\quad L R P 5^{+/-}$mice have low BMD
iii. LRP5 loss-of-function mutations cause osteoporosis-pseudoglioma syndrome (OPPG)
iv. LRP5 gain-of-function mutations cause high BMD
v. LRP5 haploinsufficiency causes familial exudative retinopathy (FEVR) and/or low BMD
i. $\quad$ A745V has been documented in FEVR
A745V
ii. Alanine to valine missense mutations in LRP5 have been associated with low BMD
iii. $\quad \mathrm{A} 745 \mathrm{~V}$ is consequential in in silico models
iv. A745 is conserved among mammals, birds, snakes, fish, and Drosophila
v. A745 is near W734 and N740 in the ligand-binding $3^{\text {rd }} \beta$-propeller domain
i. Anabolic response of bone to mechanical stress is reduced in LRP5 loss-of-function mice and enhanced in LRP5 gain-of-function mice
ii. In men, exon 9 and 10 polymorphisms negatively influence the relationship between $\mathrm{BMD}$ and physical activity, as measured by activity questionnaire
iii. The subject experienced his first fracture at the age of 18,18-months after he began distance running, consistently running 60-80 miles per week for one year
iv. The subject's threshold to fracture rapidly and steadily decreased with continued distance running

FIGURE 4 | A summary of the key evidence supporting the role of $\angle R P 5$, the A745V variant, and mechanical stress in the etiology of the subject's osteoporosis. Each category of evidence builds upon, and is inset within, the previous category. The following references correspond to each line of evidence: LRP5 (i). Trajanoska et al. (5) (ii). Sawakami et al. (17), Clement-Lacroix et al. (16), Yadav et al. (18) (iii). Gong et al. (6), Joiner et al. (1) (iv). Johnson et al. (30), Johnson (7) (v). Toomes et al. (11), Qin et al. (10). A745V (i). Pefkianaki et al. (35) (ii). Brixen et al. (32), Estrada et al. (3) (iii). Pefkianaki et al. (35) (iv). NCBl sequence analyzer and alignment tools were used to assess conservation (v). Gong et al. (6), Joiner et al. (1). Mechanical Stress (i). Sawakami et al. (17), Zhao et al. (29), Robinson et al. (24), Johnson (7), Niziolek et al. (25) and others (see text) (ii). Brixen et al. (32), Kiel et al. (31) (iii, iv). Information from the subject's medical history.

is attributable to a congenital genetic defect, why did it only manifest with fractures over 1 year into his running career when he was a young adult? The discrepancy between the father's and son's BMDs may be explained, in part, by the variable expressivity observed repeatedly with LRP5 mutations. In the first report of this $\mathrm{A} 745 \mathrm{~V}$ variant, the carrier father exhibited only subclinical symptoms (35); and probands heterozygous for inherited LRP5 mutations often exhibit BMDs significantly lower than those of their carrier parents $(8,9)$. It is also possible that the father's higher BMI $\left(37.2 \mathrm{~kg} / \mathrm{m}^{2}\right)$ was somewhat protective for his $\mathrm{BMD}$, or that it artifactually increased his $\mathrm{BMD}$. Adipose tissue can inflate DXA measurements of BMD, particularly at the spine, hip, and femur, where overestimates can approach 30\% (36). By contrast, radial DXA cannot be easily confounded by soft tissue, suggesting that the radius may be a more accurate BMD measurement site for heavier individuals
(37). Therefore, the father's radial BMD T-score of -2.6 (ageadjusted Z-score of -2.0 ) may reflect the pathogenicity of the A745V allele. Finally, and most interestingly, we speculate that the subject's running interacted with his genetics to precipitate his osteoporosis.

The proposition that the A745V polymorphism altered the anabolic response of the subject's bones to mechanical stress not only provides a potential explanation for why his phenotype is more severe than that of his father, but can also explain the peculiar chronology of his fracture history (Figure 2A). If the subject's bones were not able to adapt appropriately to the mechanical stress imposed by distance running, one would expect that he would only begin to experience fractures after a sustained period of habitual distance running, as was indeed the case in our patient. In addition, one would predict that continued distance running would continue to weaken his bones 
and increase his susceptibility to fracture, as it did. Interestingly, the subject's DXA scan revealed that his lumbar spine, total hip, and femoral neck BMD Z-scores, all of which represent load-bearing sites, were notably lower than his total body (minus head) BMD Z-score (Figure 2B). This observation mirrors the observation that LRP5 gain-of-function kindred exhibit the greatest increases in BMD at load-bearing sites (30). Notably, the subject's phenotype was more severe at the lumbar spine than at the hip and femur. Counterintuitively, this is also what the mechanotransduction model predicts. Although the spine, hip, and femur are all load-bearing sites, LRP5 polymorphisms have been reported to alter mechanotransduction in trabecular bone more so than in cortical bone, and the spine has the highest proportion of trabecular bone of these sites (26). The mechanical stress response model is further consistent with data from LRP5 mouse models, which collectively show that $L R P 5$ gain-of-function increases bone formation specifically in response to mechanical stress and that LRP5 loss-of-function reduces the response of bone to mechanical stress in a dosedependent manner $(17,24,25,29)$. Furthermore, results of the Framingham Cohort and Odense Androgen Studies suggest that $L R P 5$ polymorphisms can affect the interaction between physical activity and BMD in men, such that men carrying particular polymorphisms do not appear experience the increases in BMD usually associated with weight-bearing activities. Notably, the physical activity data from these studies were limited to selfreport questionnaires $(31,32)$ (Figure 4).

Our report has certain limitations, chief among these being that the subject had no DXA scans available for comparison before his first tibial stress fracture or during his running career. Therefore, we cannot rule out the possibility that the LRP5 mutation substantially impacted his BMD before the start of his running career, or confirm that his BMD decreased with continued running (as suggested by his decreasing mileage threshold to fracture). We also could not assess the degree to which other factors, such as the subject's ulcerative colitis or

\section{REFERENCES}

1. Joiner DM, Ke J, Zhong Z, Xu HE, Williams BO. LRP5 and LRP6 in development and disease. Trends Endocrinol Metab. (2013) 24:31-9. doi: 10.1016/j.tem.2012.10.003

2. Brent Richards J, Zheng HF, Spector TD. Genetics of osteoporosis from genome-wide association studies: advances and challenges. Nat Rev Genet. (2012) 13:576-88. doi: 10.1038/n rg3228

3. Estrada K, Styrkarsdottir U, Evangelou E, Hsu YH, Duncan EL, Ntzani EE, et al. Genome-wide meta-analysis identifies 56 bone mineral density loci and reveals 14 loci associated with risk of fracture. Nat Genet. (2012) 44:491-501. doi: 10.1038/ng.2249

4. Rivadeneira F, Styrkársdottir U, Estrada K, Halldórsson BV, Hsu YH, Richards JB, et al. Twenty bone-mineral-density loci identified by large-scale metaanalysis of genome-wide association studies. Nat Genet. (2009) 41:1199-206. doi: $10.1038 /$ ng. 446

5. Trajanoska K, Morris JA, Oei L, Zheng H, Evans DM, Kiel DP, et al. Assessment of the genetic and clinical determinants of fracture risk : genome wide association and mendelian randomisation study. $\mathrm{Br} \mathrm{Med} J$. (2018) 362:1-14. doi: 10.1136/bmj.k3225 nutritional status, may have independently, or by interacting with the A745V variant, contributed to the subject's low BMD. In fact, at the time of diagnosis, when the $\mathrm{A} 745 \mathrm{~V}$ variant was undocumented and its significance unrecognized, Relative Energy Deficiency in Sport (RED-S) was proposed as a diagnosis of exclusion $(33,34)$. While the subject's normal BMI (19$22 \mathrm{~kg} / \mathrm{m}^{2}$ ) and endocrine assessments made this a less likely diagnosis, it remains possible that insufficient nutritional intake during the high-mileage period of his running career contributed to some extent to his low BMD. Nevertheless, the fact that this young man has osteoporosis, harbors a rare mutation in a gene that is known to modify the response of bone to mechanical stress in animal models (perhaps in a sexspecific manner), and underwent a discrete period of intense mechanical loading during which he became increasingly prone to fracture, suggests that the subject may represent the first documented case of a genetic mutation that contributes to osteoporosis, in part, by altering the anabolic response of bone to mechanical stress. Future work in needed to enhance our understanding of the genetic contributions of LRP5 to mechanotransduction in bone.

\section{ETHICS STATEMENT}

Written informed consent was obtained from the participant for the publication of this case report and any potentiallyidentifying information/images.

\section{AUTHOR CONTRIBUTIONS}

All authors listed have made a substantial, direct and intellectual contribution to the work, and approved it for publication.

\section{FUNDING}

This work was supported by K24 HD071843 (grant to MM).
6. Gong Y, Slee R, Fukai N, Rawadi G, Roman-Roman S, Reginato A, et al. LDL Receptor-related protein 5 (LRP5) affects bone accrual and eye development. Cell. (2001) 107:513-23.

7. Johnson ML. The high bone mass family - the role of Wnt/Lrp5 signaling in the regulation of bone mass. J Musc Neuronal Inter. (2004) 4:135-8.

8. Hartikka H, Mäkitie O, Männikkö M, Doria AS, Daneman A, Cole WG, et al. Heterozygous mutations in the LDL receptor-related protein 5 (LRP5) gene are associated with primary osteoporosis in children. J Bone Min Res. (2005) 20:783-9. doi: 10.1359/JBMR.050101

9. Korvala J, Jüppner H, Mäkitie O, Sochett E, Schnabel D, Mora S, et al. Mutations in LRP5 cause primary osteoporosis without features of OI by reducing Wnt signaling activity. BMC Med Genet. (2012) 13:26. doi: 10.1186/1471-2350-13-26

10. Qin M, Hayashi H, Oshima K, Tahira T, Hayashi K, Kondo H. Complexity of the genotype-phenotype correlation in familial exudative vitreoretinopathy with mutations im the LRP5 and/or FZD4 genes. Hum Mut. (2005) 26:104-12. doi: 10.1002/humu.20191

11. Toomes C, Bottomley HM, Jackson RM, Towns KV, Scott S, Mackey DA, et al. Mutations in LRP5 or FZD4 underlie the common familial exudative vitreoretinopathy locus on chromosome 11q. Am J Hum Genet. (2004) 74:721-30. doi: $10.1086 / 383202$ 
12. Armstrong VJ, Muzylak M, Sunters A, Zaman G, Saxon LK, Price JS, et al. $\mathrm{Wnt} / \beta$-catenin signaling is a component of osteoblastic bone cell early responses to load-bearing and requires estrogen receptor $\alpha$. J Biol Chem. (2007) 282:20715-27. doi: 10.1074/jbc.M703224200

13. Balemans W, Wim VH. Minireview: the genetics of low-density lipoprotein receptor-related protein 5 in bone: a story of extremes. Endocrinology. (2007) 148:2622-9. doi: 10.1210/en.2006-1352

14. Dubrow SA, Hruby PM, Akhter MP. Gender specific LRP5 influences on trabecular bone structure and strength. J Musc Neuronal Inter. (2007) 7:166-73.

15. Ferrari SL, Deutsch S, Choudhury U, Chevalley T, Bonjour J-P, Dermitzakis ET, et al. Polymorphisms in the low-density lipoprotein receptor-related protein 5 (LRP5) gene are associated with variation in vertebral bone mass, vertebral bone size, and stature in whites. Am J Hum Genet. (2004) 74:866-75. doi: 10.1086/420771

16. Clement-Lacroix P, Ai M, Morvan F, Roman-Roman S, Vayssiere B, Belleville C, et al. Lrp5-independent activation of Wnt signaling by lithium chloride increases bone formation and bone mass in mice. Proc Natl Acad Sci USA. (2005) 102:17406-11. doi: 10.1073/pnas.0505259102

17. Sawakami K, Robling AG, Ai M, Pitner ND, Liu D, Warden SJ, et al. The Wnt co-receptor LRP5 is essential for skeletal mechanotransduction but not for the anabolic bone response to parathyroid hormone treatment. J Biol Chem. (2006) 28:23698-711. doi: 10.1074/jbc.M601000200

18. Yadav VK, Ryu JH, Suda N, Tanaka KF, Gingrich JA, Schütz G, et al. Lrp5 controls bone formation by inhibiting serotonin synthesis in the duodenum. Cell. (2008) 135:825-37. doi: 10.1016/j.cell.2008.09.059

19. Almeida M, Han L, Bellido T, Manolagas SC, Kousteni S. Wnt proteins prevent apoptosis of both uncommitted osteoblast progenitors and differentiated osteoblast by $\beta$-catenin-dependent and -independent signaling cascades involving Src/ERK and phosphatidylinositol 3-kinase/AKT. J Biol Chem. (2005) 280:41342-51. doi: 10.1074/jbc.M502168200

20. Glass DA, Bialek P, Ahn JD, Starbuck M, Patel MS, Clevers H, et al. Canonical Wnt signaling in differentiated osteoblasts controls osteoclast differentiation. Dev Cell. (2005) 8:751-64. doi: 10.1016/j.devcel.2005.02.017

21. Kolpakova E, Olsen B. Wnt/ $\beta$-catenin-a canonical tale of cellfate choice in the vertebrate skeleton. Dev Cell. (2005) 8:626-7. doi: 10.1016/j.devcel.2005.04.008

22. Manolagas SC, Almeida M. Gone with the Wnts: $\beta$-catenin, T-cell factor, forkhead box $\mathrm{O}$, and oxidative stress in age-dependent diseases of bone, lipid, and glucose metabolism. Mol Endocrinol. (2007) 21:2605-14. doi: 10.1210/me.2007-0259

23. Papachroni KK, Karatzas DN, Papavassiliou KA, Basdra EK, Papavassiliou AG. Mechanotransduction in osteoblast regulation and bone disease. Trends Mol Med. (2009) 15:208-16. doi: 10.1016/j.molmed.2009.03.001

24. Robinson JA, Chatterjee-Kishore M, Yaworsky PJ, Cullen DM, Zhao $\mathrm{W}$, Li C, et al. Wnt/ $\beta$-catenin signaling is a normal physiological response to mechanical loading in bone. J Biol Chem. (2006) 281:31720-8. doi: 10.1074/jbc.M602308200

25. Niziolek PJ, Warman ML, Robling AG. Mechanotransduction in bone tissue: The $\mathrm{A} 214 \mathrm{~V}$ and $\mathrm{G} 171 \mathrm{~V}$ mutations in Lrp5 enhance load-induced osteogenesis in a surface-selective manner. Bone. (2012) 51:459-65. doi: 10.1016/j.bone.2012.05.023

26. Saxon LK, Jackson BF, Sugiyama T, Lanyon LE, Price JS. Analysis of multiple bone responses to graded strains above functional levels, and to disuse, in mice in vivo show that the human Lrp5 G171V High Bone Mass mutation increases the osteogenic response to loading but that lack of Lrp5 activity reduces it. Bone. (2011) 49:184-93. doi: 10.1016/j.bone.2011. 03.683

27. Javaheri B, Stern AR, Lara N, Dallas M, Zhao H, Liu Y, et al. Deletion of a single $\beta$-catenin allele in osteocytes abolishes the bone anabolic response to loading. J Bone Min Res. (2014) 29:705-15. doi: 10.1002/jbmr.2064

28. Tu X, Delgado-Calle J, Condon KW, Maycas M, Zhang H, Carlesso $\mathrm{N}$, et al. Osteocytes mediate the anabolic actions of canonical Wnt/ $\mathrm{\beta}$ catenin signaling in bone. Proc Natl Acad Sci USA. (2015) 112:E478-E486. doi: 10.1073/pnas.1409857112

29. Zhao L, Shim JW, Dodge TR, Robling AG, Yokota H. Inactivation of Lrp5 in osteocytes reduces Young's modulus and responsiveness to the mechanical loading. Bone. (2013) 54:35-43. doi: 10.1016/j.bone.2013.01.033

30. Johnson M, Picconi B, Recker R. The gene for high bone mass. Endocrinologist. (2002) 12:445-53. doi: 10.1097/01.ten.0000029417.07585.81

31. Kiel DP, Ferrari SL, Cupples LA, Karasik D, Manen D, Imamovic A, et al. Genetic variation at the low density lipoprotein receptor-related protein 5 (LRP5) locus modulates Wnt signaling and the relationship of physical activity with bone mineral density in men. Bone. (2007) 40:587-96. doi: 10.1016/j.bone.2006.09.029

32. Brixen K, Beckers S, Peeters A, Piters E, Balemans W, Nielsen TL, et al. Polymorphisms in the low-density lipoprotein receptor-related protein 5 (LRP5) gene are associated with peak bone mass in non-sedentary men: results from the Odense Androgen Study. Calcif Tissue Int. (2007) 81:421-9. doi: 10.1007/s00223-007-9088-z

33. Elliott-Sale K, Tenforde A, Parziale A, Holtzman B, Ackerman K. Endocrine effects of relative energy deficiency in sport. Int J Sport Nutr Exerc Metab. (2018) 28:335-49. doi: 10.1123/ijsnem.2018-0127

34. Mountjoy M, Sundgot-Borgen JK, Burke LM, Ackerman KE, Blauwet $\mathrm{C}$, Constantini $\mathrm{N}$, et al. IOC consensus statement on relative energy deficiency in sport (RED-S): 2018 update. Br J Sports Med. (2018) 52:687-97. doi: 10.1136/bjsports-2018-099193

35. Pefkianaki M, Hasanreisoglu M, Suchy SF, Shields CL. Familial exudative vitreoretinopathy with a novel LRP5 mutation. J Pediatr Ophthalmol Strabism. (2016) 53:39-42. doi: 10.3928/01913913-20160719-02

36. Bolotin HH. DXA in vivo BMD methodology: an erroneous and misleading research and clinical gauge of bone mineral status, bone fragility, and bone remodelling. Bone. (2007) 41:138-54. doi: 10.1016/j.bone.2007.02.022

37. Trivitayaratana $\mathrm{W}$, Trivitayaratana $\mathrm{P}$. The accuracy of bone mineral density at the distal radius on non-forearm osteoporosis identification. J Med Assoc. (2001) 84:566-71.

Conflict of Interest Statement: The authors declare that the research was conducted in the absence of any commercial or financial relationships that could be construed as a potential conflict of interest.

Copyright (c) 2019 Norwitz, Mota, Misra and Ackerman. This is an open-access article distributed under the terms of the Creative Commons Attribution License (CC $B Y)$. The use, distribution or reproduction in other forums is permitted, provided the original author(s) and the copyright owner(s) are credited and that the original publication in this journal is cited, in accordance with accepted academic practice. No use, distribution or reproduction is permitted which does not comply with these terms. 